\title{
SELECTIVE ADVANTAGE OF HETEROZYGOTES AT B BLOOD GROUP LOCUS IN THE CHICKEN
}

\author{
YOSHIHISA FUJIO \\ Laboratory of Animal Genetics, Faculty of Agriculture, \\ Nagoya University, Chigusa-ku, Nagoya 464
}

Received March 1, 1971

A multiple allelic system at a locus such as a B blood group system of the chicken can give rise to genotypes with different viabilities. Under certain conditions, the genes involving such a system can exist in a state of equilibrium, being known as a balanced polymorphism. In the general case, a necessary condition for stable polymorphism is that the viability of each homozygote be less than the mean viability in the population. Roughly speaking, the heterozygotes can be more viable than any of the homozygotes (Mandel 1959).

Two or more alleles of B blood group system were demonstrated to exists in several closed populations of chickens (Briles et al. 1957; Gilmour 1959; Fujio and Kondo 1970). This type of evidence argues powerfully for heterozygous advantage. Fujio and Kondo (1970) revealed apparent selective advantage of heterozygotes, that is, the observed frequency of heterozygote in each population was higher than the expected one. Several workers have shown evidence that heterozygotes of blood group loci were superior in term of fertility, hatchability, viability, and egg production (Briles and Krueger 1955; Briles and Allen 1961; Allen 1962; Allen and Gilmour 1962; Morton et al. 1965).

The superiority of heterozygotes in regard to each character such as fertility, hatchability, and viability should be proved by the cross experiment. The present paper is to point out an abnormal segregation of B blood group alleles, and to demonstrate the superiority of heterozygotes in hatchability, an important component of fitness.

\section{MATERIALS AND METHODS}

Four inbred strains and one breed were used for the present work. These four inbred strains were BM-C,NG-B,WL-M, and CON. The birds of these strains were homozygous for the genes determining blood group antigens as described previously (Fujio et al. 1970). In addition, one breed was Rhode Island Red (RIR). Its genotype concerned with the blood group gene $B$ was determined by the cross test. The genotype of $\mathrm{B}$ blood group system and plumage color in four inbred strains, one breed, and their $F_{1}$ hybrids are summarized in Table 1.

The serological procedures and the nomenclature used in the present work had been previously reported (Fujio et al. 1970). All blood samples were collected from wing vein 
Table 1. The genotype of B blood group system and of other character in four inbred strains, one breed, and their $F_{1}$ hybrids

\begin{tabular}{llcc}
\hline & \multirow{2}{*}{ Origin } & \multicolumn{2}{c}{ Genotype of } \\
\cline { 3 - 4 } & & B blood group & Plumage color \\
\hline Strain & & & \\
BM-C & Black Minorca C & $B^{A} / B^{A}$ & $i / i ; E / E$ \\
NG-B & Nagoya B & $B^{B} / B^{B}$ & $i / i ; e / e$ \\
RIR & Rhode Island Red & $B^{G} / B^{G}$ & $i / i ; e^{y} / e^{y}$ \\
CON & Cross between & $B^{K} / B^{K}$ & $i / i ; e / e$ \\
& White Cornish and & & \\
WL-M & New Hampshire & & \\
$F_{1}$ hybrid & White Leghorn M & $B^{M} / B^{M}$ & \\
NG-B $\times \mathrm{BM}-\mathrm{C}$ & & & \\
RIR $\times \mathrm{BM}-\mathrm{C}$ & & $B^{A} / B^{B}$ & $i / i ; E / e$ \\
$\mathrm{BM}-\mathrm{C} \times \mathrm{CON}$ & & $B^{A} / B^{G}$ & $i / i ; E / e^{y}$ \\
$\mathrm{BM}-\mathrm{C} \times \mathrm{WL}-\mathrm{M}$ & & $B^{A} / B^{K}$ & $i / i ; E / e$ \\
$\mathrm{NG}-\mathrm{B} \times \mathrm{CON}$ & & $B^{A} / B^{M}$ & $I / i$ \\
& & $B^{B} / B^{K}$ & $i / i ; e / e$ \\
\hline
\end{tabular}

of 3 weeks old chicks. Detection of antigens was performed with five iso-immune antisera involved in the B blood group system (named $A, B, G, K$, and $M$ ). For hemagglutination tests, the titer of antisera was adjusted with saline to $1: 4$, and the twofold serial dilutions of each antiserum were prepared in a plastic agglutination plate. Equal volume of 2 percent red cell suspension $(\mathrm{V} / \mathrm{V})$ was added to $0.1 \mathrm{ml}$. of each diluted antiserum. Hemagglutination patterns were recorded at 30-60 minutes after mixing.

\section{RESULTS}

Table 2 shows $\mathrm{F}_{2}$ segregation of the $\mathrm{B}$ blood group alleles. Their segregation ratios do not agree with Mendelian segregation ratio, that is, occurrence of heterozygous genotypes is higher than that expected on the basis of Mendelian segregation in all cases. The differences between the observed numbers and expected ones were statistically significant in all cases except one.

The $\mathrm{F}_{2}$ segregations of the other character genes, namely the black-red melanin distribution $\left(E, e\right.$, and $\left.e^{y}\right)$ and dominant white $(I)$ in the color of plumage were simultaneously examined as control in the crosses for the B blood group alleles (Table 3 ). Their segregation ratios were highly accordant with Mendelian segregation ratio $(\mathrm{P}>$ 0.80). Table 3 also shows the $F_{2}$ segregation of the other character genes such as those governing diluting black plumage $(B l)$, red cell agglutinogen in response to tissue hemagglutinin $(T h)$, and creeper $(C p)$ which were examined in the course of other experiments at our laboratory. It indicated that their segregation ratios corresponded to Mendelian segregation ratio $(\mathrm{P}>0.50)$. Thus it is recognized that the $\mathrm{F}_{2}$ segregation of only B blood group alleles is abnormal. 
Table 2. $\mathrm{F}_{2}$ segregation of antigen in $\mathrm{B}$ blood group locus $\mathrm{F}_{2}(\mathrm{NG}-\mathrm{B} \times \mathrm{BM}-\mathrm{C})$

\begin{tabular}{llllll}
\hline \hline & $B^{A} / B^{A}$ & $B^{B} / B^{B}$ & $B^{A} / B^{B}$ & Total & $\chi^{2}$ \\
\hline Observed & 35 & 50 & 115 & 200 & 6.750 \\
Expected & 50.0 & 50.0 & 100.0 & 200.0 & \\
\hline
\end{tabular}

$\mathrm{F}_{2}(\mathrm{RIR} \times \mathrm{BM}-\mathrm{C})$

\begin{tabular}{llllll}
\hline \hline & $B^{A} / B^{A}$ & $B^{G} / B^{G}$ & $B^{A} / B^{G}$ & Total & $\chi^{2}$ \\
\hline Observed & 26 & 19 & 61 & 106 & 3.339 \\
Expected & 26.5 & 26.5 & 53.0 & 106.0 & \\
\hline
\end{tabular}

$\mathrm{F}_{2}(\mathrm{BM}-\mathrm{C} \times \mathrm{CON})$

\begin{tabular}{llllll}
\hline \hline & $B^{A} / B^{A}$ & $B^{K} / B^{K}$ & $B^{A} / B^{K}$ & Total & $\chi^{2}$ \\
\hline Observed & 50 & 30 & 122 & 202 & 12.692 \\
Expected & 50.5 & 50.5 & 101.0 & 202.0 & \\
\hline
\end{tabular}

$\mathrm{F}_{2}(\mathrm{BM}-\mathrm{C} \times \mathrm{WL}-\mathrm{M})$

\begin{tabular}{lccccc}
\hline \hline & $B^{A} / B^{A}$ & $B^{M} / B^{M}$ & $B^{A} / B^{M}$ & Total & $\chi^{2}$ \\
\hline Observed & 25 & 18 & 83 & 126 & 13.476 \\
Expected & 31.5 & 31.5 & 63.0 & 126.0 & \\
\hline
\end{tabular}

$\mathrm{F}_{2}(\mathrm{NG}-\mathrm{B} \times \mathrm{CON})$

\begin{tabular}{lccccc}
\hline & $B^{B} / B^{B}$ & $B^{K} / B^{K}$ & $B^{B} / B^{K}$ & Total & $\chi^{2}$ \\
\hline Observed & 24 & 30 & 136 & 190 & 39.389 \\
Expected & 47.5 & 47.5 & 95.0 & 190.0 & \\
\hline
\end{tabular}

The reciprocal backcross tests were performed as shown in Table 4 . In the crosses between sire $B^{B} / B^{B}$ and dam $B^{B} / B^{K}$ and between sire $B^{B} / B^{K}$ and dam $B^{B} / B^{B}$, a highly significant deviation from the Mendelian proportion $(1: 1)$ was observed, that is, occurrence of heterozygous genotypes was higher than that of homozygous genotypes. Similar result was obtained in the crosses between sire $B^{K} / B^{K}$ and dam $B^{B} / B^{K}$, and between sire $B^{B} / B^{K}$ and dam $B^{K} / B^{K}$. Thus, it suggested that an abnormal seggregation was not due to a maternal effect.

If the abnormal segregation is due to a difference in embryonic mortalily associated with the genotypes, the hatchability should be varied for the genotypes. Fertilized eggs of each genotype were calculated by assuming that the segregation of fertilized eggs in $\mathrm{F}_{2}$ and backcross had corresponded to Mendelian ratio, and the hatchability of each genotype was estimated. The observed numbers at 3 weeks old were representative of the numbers at hatching, since the survival rate of the newly hatched chicks to 3 weeks old was almost 100 percent. Tables 5 and 6 represent a significant difference in hatch- 
Table 3. $F_{2}$ segregation of several characters Plumage color in the crosses for the $\mathrm{B}$ blood group alleles $\mathrm{F}_{2}(\mathrm{NG}-\mathrm{B} \times \mathrm{BM}-\mathrm{C})$

\begin{tabular}{|c|c|c|c|c|c|}
\hline & $E / E$ & $e / e$ & $E / e$ & Total & $\chi^{2}$ \\
\hline Observed & 63 & 65 & 118 & 246 & 0.438 \\
\hline Expected & 61.5 & 61.5 & 123.0 & 246.0 & \\
\hline
\end{tabular}

$\mathrm{F}_{2}(\mathrm{RIR} \times \mathrm{BM}-\mathrm{C})$

\begin{tabular}{lllllc}
\hline \hline & $E / E$ & $e^{y} / e^{y}$ & $E / e^{y}$ & Total & $\chi^{2}$ \\
\hline Observed & 26 & 26 & 58 & 110 & 0.327 \\
Expected & 27.5 & 27.5 & 55.0 & 110.0 & \\
\hline
\end{tabular}

$\mathrm{F}_{2}(\mathrm{BM}-\mathrm{C} \times \mathrm{WL}-\mathrm{M})$

\begin{tabular}{llllll}
\hline \hline & $I / I$ & $i / i$ & $I / i$ & Total & $\chi^{2}$ \\
\hline Observed & 41 & 37 & 73 & 151 & 0.363 \\
Expected & 37.75 & 37.75 & 75.50 & 151.0 & \\
\hline
\end{tabular}

Diluting black plumage

\begin{tabular}{llllll}
\hline & $B l / B l$ & $b l / b l$ & $B l / b l$ & Total & $\chi^{2}$ \\
\hline Observed & 52 & 48 & 96 & 196 & 0.244 \\
Expected & 49.0 & 49.0 & 98.0 & 196.0 & \\
\hline
\end{tabular}

$T h$ agglutinogen in response to tissue hemagglutinin

\begin{tabular}{llllll}
\hline & Th/Th & th/th & Th/th & Total & $\chi^{2}$ \\
\hline Observed & 36 & 30 & 71 & 137 & 0.795 \\
Expected & 34.15 & 34.15 & 68.30 & 137.0 & \\
\hline
\end{tabular}

Creeper

\begin{tabular}{llllll}
\hline \hline & $C p / C p$ & $c p / c p$ & $C p / c p$ & Total & $\chi^{2}$ \\
\hline Observed & 55 & 48 & 110 & 213 & 0.690 \\
Expected & 53.25 & 53.25 & 106.5 & 213.0 & \\
\hline
\end{tabular}

ability as compared homozygotes with heterozygotes. Heterozygotes showed higher hatchability than homozygotes. Furthermore it was observed that hatchability of heterozygotes was same as that of $F_{1}$ hybrids in each combination of the alleles.

The hatchability of each homozygote was lower than the mean hatchability in $\mathrm{F}_{2}$ and backcross. Homozygote showed varied hatchability from one cross to another. For example, the hatchability of $B^{A} / B^{A}$ were $53.8,59.9,65.0$, and 76.3 percent in $\mathrm{F}_{2}$ segregation 
Table 4. Segregation of antigen in B blood group locus in the backcrosses

$\mathrm{NG}-\mathrm{B}(\hat{\mathrm{o}}) \times \mathrm{F}_{1}(\mathrm{NG}-\mathrm{B} \times \mathrm{CON})$ (우)

\begin{tabular}{lcclc}
\hline & $B^{B} / B^{B}$ & $B^{B} / B^{K}$ & Total & $\chi^{2}$ \\
\hline Observed & 25 & 62 & 87 & 15.747 \\
Expected & 43.5 & 43.5 & 87.0 & \\
\hline
\end{tabular}

$\mathrm{F}_{1}(\mathrm{NG}-\mathrm{B} \times \mathrm{CON})($ () $) \times \mathrm{NG}-\mathrm{B}$ (우)

\begin{tabular}{lllll}
\hline \hline & $B^{B} / B^{B}$ & $B^{B} / B^{K}$ & Total & $\chi^{2}$ \\
\hline Observed & 27 & 63 & 90 & 14.400 \\
Expected & 45.0 & 45.0 & 90.0 & \\
\hline
\end{tabular}

$\mathrm{CON}(\hat{O}) \times \mathrm{F}_{1}(\mathrm{NG}-\mathrm{B} \times \mathrm{CON})$ (우)

\begin{tabular}{llllc}
\hline & $B^{K} / B^{K}$ & $B^{B} / B^{K}$ & Total & $\chi^{2}$ \\
\hline Observed & 18 & 57 & 75 & 20.280 \\
Expected & 37.5 & 37.5 & 75.0 & \\
\hline
\end{tabular}

$\mathrm{F}_{1}(\mathrm{NG}-\mathrm{B} \times \mathrm{CON})(\hat{b}) \times \mathrm{CON}($ 우 $)$

\begin{tabular}{lllll}
\hline & $B^{K} / B^{K}$ & $B^{B} / B^{K}$ & Total & $\chi^{2}$ \\
\hline Observed & 22 & 62 & 84 & 19.047 \\
Expected & 42.0 & 42.0 & 84.0 & \\
\hline
\end{tabular}

of NG-B $\times$ BM-C, BM-C $\times$ WL-M, RIR $\times \mathrm{BM}-\mathrm{C}$, and BM-C $\times C O N$, respectively. The variation in hatchability of homozygote could be attributed to the partner. The genetic make-up of partner may have influence on progeny performance.

Although quantitative analysis on embryonic mortality was not carried out through the incubation period, it was observed that the main contributions to embryonic mortality had come from the high mortality periods of 16-21 days of incubation. Thus, the difference in embryonic mortality among genotypes of the B blood group locus is responsible for the cause of an abnormal segregation.

\section{DISCUSSION}

The deviation of genotypic class numbers from those expected was found in $\mathrm{F}_{2}$ and backcross segregation of only B blood group system due to the fact that the number of heterozygous genotype is larger than that expected. The supposition may not always be justified that segregation of B blood group genotypic classes is accordant with Mendelian ratio. The existence of this disturbance in the ratio underlines the need to draw attention on itself, when blood grouping tests are carried out for the purpose of progeny test, genetic analysis and so on. 
Table 5. Effects of the genotypes of B blood group system on hatchability $\mathrm{NG}-\mathrm{B} \times \mathrm{BM}-\mathrm{C}$

\begin{tabular}{llllc}
\hline \multicolumn{1}{c}{ Genotype } & $B^{A} / B^{A}$ & $B^{B} / B^{B}$ & $B^{A} / B^{B}$ & Total or mean \\
\hline No. of hatch & 35 & 50 & 115 & 200 \\
No. of fertile eggs & 60 & 60 & 120 & 240 \\
Hatchability of $\mathrm{F}_{2}$ & $53.8 \%$ & $83.3 \%$ & $95.3 \%$ & $83.3 \%$ \\
Hatchability of $\mathrm{F}_{1}$ & & & $96.7 \%$ & $96.7 \%$ \\
\hline
\end{tabular}

$\mathrm{RIR} \times \mathrm{BM}-\mathrm{C}$

\begin{tabular}{lllcc}
\hline \multicolumn{1}{c}{ Genotype } & $B^{A} / B^{A}$ & $B^{G} / B^{G}$ & $B^{A} / B^{G}$ & Total or mean \\
\hline No. of hatch & 26 & 19 & 61 & 106 \\
No. of fertile eggs & 40 & 40 & 80 & 160 \\
Hatchability of $\mathrm{F}_{2}$ & $65.0 \%$ & $47.6 \%$ & $76.3 \%$ & $66.3 \%$ \\
Hatchability of $\mathrm{F}_{1}$ & & & $78.6 \%$ & $78.6 \%$ \\
\hline
\end{tabular}

$\mathrm{BM}-\mathrm{C} \times \mathrm{CON}$

\begin{tabular}{llllc}
\hline \multicolumn{1}{c}{ Genotype } & $B^{A} / B^{A}$ & $B^{K} / B^{K}$ & $B^{A} / B^{K}$ & Total or mean \\
\hline No. of hatch & 50 & 30 & 122 & 202 \\
No. of fertile eggs & 65.5 & 65.5 & 131.0 & 262 \\
Hatchability of $\mathrm{F}_{2}$ & $76.3 \%$ & $45.8 \%$ & $93.1 \%$ & $77.1 \%$ \\
Hatchability of $\mathrm{F}_{1}$ & & & $96.3 \%$ & $96.3 \%$ \\
\hline
\end{tabular}

$\mathrm{BM}-\mathrm{C} \times \mathrm{WL}-\mathrm{M}$

\begin{tabular}{llllc}
\hline \multicolumn{1}{c}{ Genotype } & $B^{A} / B^{A}$ & $B^{M} / B^{M}$ & $B^{A} / B^{M}$ & Total or mean \\
\hline No. of hatch & 25 & 18 & 83 & 126 \\
No. of fertile eggs & 41.75 & 41.75 & 83.5 & 167 \\
Hatchability of $\mathrm{F}_{2}$ & $59.9 \%$ & $43.1 \%$ & $99.4 \%$ & $75.4 \%$ \\
Hatchability of $\mathrm{F}_{1}$ & & & $96.1 \%$ & $96.1 \%$ \\
\hline
\end{tabular}

$\mathrm{NG}-\mathrm{B} \times \mathrm{CON}$

\begin{tabular}{llllc}
\hline \multicolumn{1}{c}{ Genotype } & $B^{B} / B^{B}$ & $B^{K} / B^{K}$ & $B^{B} / B^{K}$ & Total or mean \\
\hline No. of hatch & 24 & 30 & 136 & 190 \\
No. of fertile eggs & 70.25 & 70.25 & 140.5 & 281 \\
Hatchability of $\mathrm{F}_{2}$ & $34.2 \%$ & $42.7 \%$ & $96.8 \%$ & $67.6 \%$ \\
Hatchability of $\mathrm{F}_{1}$ & & & $96.3 \%$ & $96.3 \%$ \\
\hline
\end{tabular}

The mechanism operating to cause the observed disturbance in the segregation ratio should propose two suppositions. The first suggests an abnormal segregation of oocytes in the dam during meiosis. Perramon and Merat (1968) reported that a highly significant heterogeneity in segregation ratios between heterozygous dams at blood group loci $W^{6} / W^{0}$ and $R^{4} / R^{0}$ was observed in crosses sire $W^{0} / W^{0} \times$ dam $W^{6} / W^{0}$ of Wyandotte strain 
Table 6. Effects of the genotypes of B blood group system on hatchability

\begin{tabular}{lllc} 
NG-B $(\hat{\rho}) \times \mathrm{F}_{1}(\mathrm{NG}-\mathrm{B} \times \mathrm{CON})$ & $($ 우 $)$ & \\
\hline \multicolumn{1}{c}{ Genotypes } & $B^{B} / B^{B}$ & $B^{B} / B^{K}$ & Total or mean \\
\hline No. of hatch & 25 & 62 & 87 \\
No. of fertile eggs & 63 & 63 & 126 \\
Hatchability & $39.7 \%$ & $98.4 \%$ & $69.0 \%$ \\
\hline
\end{tabular}

$\mathrm{F}_{1}(\mathrm{NG}-\mathrm{B} \times \mathrm{CON})(\hat{o}) \times \mathrm{NG}-\mathrm{B}($ 우 $)$

\begin{tabular}{lllc}
\hline \multicolumn{1}{c}{ Genotypes } & $B^{B} / B^{B}$ & $B^{B} / B^{K}$ & Total or mean \\
\hline No. of hatch & 27 & 63 & 90 \\
No. of fertile eggs & 66.5 & 66.5 & 133 \\
Hatchability & $40.6 \%$ & $94.7 \%$ & $67.7 \%$ \\
\hline
\end{tabular}

$\mathrm{CON}(\hat{o}) \times \mathrm{F}_{1}(\mathrm{NG}-\mathrm{B} \times \mathrm{CON})($ 우 $)$

\begin{tabular}{lllc}
\hline \multicolumn{1}{c}{ Genotypes } & $B^{K} / B^{K}$ & $B^{B} / B^{K}$ & Total or mean \\
\hline No. of hatch & 18 & 57 & 75 \\
No. of fertile eggs & 60 & 60 & 120 \\
Hatchability & $30.0 \%$ & $95.0 \%$ & $62.5 \%$ \\
\hline
\end{tabular}

$\mathrm{F}_{1}(\mathrm{NG}-\mathrm{B} \times \mathrm{CON})(\hat{\sigma}) \times \mathrm{CON}$ (우)

\begin{tabular}{lllc}
\hline \multicolumn{1}{c}{ Genotypes } & $B^{K} / B^{K}$ & $B^{B} / B^{K}$ & Total or mean \\
\hline No. of hatch & 22 & 62 & 84 \\
No. of fertile eggs & 62.5 & 62.5 & 125 \\
Hatchability & $35.2 \%$ & $99.2 \%$ & $67.2 \%$ \\
\hline
\end{tabular}

and sire $R^{0} / R^{0} \times$ dam $R^{4} / R^{0}$ of Rhode Island strain respectively. The reciprocal cross test in the present work suggested that an abnormal segregation was not due to maternal effect. However, a possibility that there is an abnormal segregation of oocytes in the dam may remain to be investigated, since small numbers of dams were used for the cross experiment in this work.

In the second supposition, a difference in embryonic mortality associated with the genotypes should be considered. Earlier works on the effects of blood groups on hatchability concerned the specialized situations of inbred lines or intercrossbreds (review by Gilmour 1960; Allen 1962; Allen and Gilmour 1962). They had analyzed the variance in hatchability associated with parental genotype. Recently, Morton et al. (1965) showed that the B blood group genotypes of zygotes but not of dams were associated with marked differences in mortality over the whole incubation periods.

The present data showed that the B blood group locus was generally overdominant in its effects on hatchability. Heterozygotes are superior in hatchability to homozygotes, and the hatchability of each homozygote is lower than the mean hatchability in $F_{2}$ and 
backcross. This fulfils the simplest of Mandel's (1959) necessary conditions for a stable polymorphism, that is, the viability of each homozygote should be less than the mean population viability in a state of equilibrium.

The estimated time of embryonic death is reasonable from the time of appearance of antigen at the B blood group system. Fujio et al. (1970) reported that several antigens of the $\mathrm{B}$ blood group system appeared at 7-12 days of incubation. It was also found by Morton et al. (1965) that the main contribution to the overall embryonic mortality came from the high mortality period from 16 to 19 days of incubation.

Thus, the evidence was obtained that the B blood group genotypes of zygotes were associated with powerful selective effects through hatchability. It is not however sufficient in itself to explain the maintenance of the stable polymorphism, since it is necessary at a next step to take into account selective effects in the other periods of the life cycle though hatchability is an important one.

\section{SUMMARY}

In cross experiment, the deviation of genotypic class numbers from those expected was found in $F_{2}$ and backcross segregation of only $B$ blood group system, due to the fact that the number of heterozygous genotypes was larger than that expected.

The B blood group genotypes of zygotes associated themselves with marked differences in embryonic mortality over the whole incubation periods, especially at periods of 16-21 days of incubation.

The hatchability of each homozygote was lower than the mean hatchability in $\mathrm{F}_{2}$ and backcross. The maintenance of stable polymorphism could be explained by differences in mortality among genotypes.

\section{ACKNOWLEDGMENT}

The author wishes to express his hearty thanks to Prof. K. Kondo for his advice and encouragements. The author also thanks to Dr. K. Nozawa of the Primate Research Institute of Kyoto University for reading the manuscript and offering his valuable suggestions.

\section{LITERATURE CITED}

Allen, C. P., 1962 The effect of parental B locus genotypes on multiple cross performance in chickens. Ann. N.Y. Acad. Sci. 97: 184-193.

Allen, C. P., and D. G. Gilmour, 1962 The B blood group system of chickens. III. The effects of two heterozygous genotypes on the survival and egg production of multiple crosses. Genetics 47: 1711-1718.

Briles, W. E., and W. F. Krueger, 1955 The effect of parental B blood group genotypes on hatchability and live-ability in Leghorn inbred lines. Poultry Sci. 34: 1182. 
Briles, W. E., C. P. Allen, and T. W. Millen, 1957 The B blood group system in chickens. I. Heterozygosity in closed populations. Genetics 42: 631-648.

Briles, W. E., and C. P. Allen, 1961 The B blood group system of chickens. II. The effects of genotype on livability and egg production in seven commercial inbred lines. Genetics 46: 1273-1293.

Fujio, Y., Y. Kanoh, and K. Kondo, 1970 Developmental changes in some blood group antigens in the chicken. Japan. J. Genetics 45: 23-33.

Fujio, Y., and K. Kondo, 1970 The B blood group polymorphism in the chicken. I. Heterozygosity in closed population of White Leghorn. Japan. J. Zootech. Sci. 41: 593-600.

Gilmour, D. G., 1959 Segregation of genes determining red cell antigens at high levels of inbreeding in chickens. Genetics 44: 14-33.

Gilmour, D. G., 1960 Blood groups in chickens. Brit. Poultry Sci. 1: 75-100.

Mandel, S. P. H., 1959 The stability of a multiple allelic system. Heredity 13: 289-302.

Morton, J. R., D. G. Gilmour, E. M. McDermid, and A. L. Ogden, 1965 Association of blood-group and protein polymorphisms with embryonic mortality in the chicken. Genetics 51: 97-107. 